\title{
Relationship among Insulin-Like Growth Factor-I, Blood Metabolites and Postpartum Ovarian Function in Dairy Cows
}

\author{
Victor Chisha ZULU ${ }^{1)}$, Yutaka SAWAMUKAI ${ }^{1) *}$, Ken NAKADA $^{1)}$, Katsuya KIDA ${ }^{2)}$ and Masaharu MORIYOSHI ${ }^{1)}$ \\ ${ }^{1)}$ Department of Obstetrics and Gynecology, Graduate School of Veterinary Medicine, Rakuno Gakuen University, 582 Bunkyodai- \\ Midorimachi, Ebetsu, Hokkaido 069-8501 and ${ }^{2)}$ Large Animal Clinic and Research Center, 612 Motonopporo, Ebetsu, Hokkaido 069- \\ 0805, Japan
}

(Received 9 November 2001/Accepted 7 May 2002)

\begin{abstract}
The relationship among nutritional status, systemic insulin-like growth factor-I (IGF-I) and ovarian function early postpartum were investigated. A total of 27 Holstein-Friesian cows, 10 that cycled normally within 20 days postpartum, 5 diagnosed with follicular cysts, 8 with persistent corpus luteum (CL) after the first ovulation postpartum and 4 with inactive ovaries were used for the study. Blood samples were collected 1-3 times per week, for 60 days pre- and postpartum, for IGF-I, progesterone, estradiol, free fatty acids (FFA), blood urea nitrogen (BUN), and aspartate aminotransferase (AST) determination. Inactive ovary and cystic cows had a higher body condition score before calving and lost more condition than normal or persistent CL cows. Immediately postpartum, IGF-I levels were higher and rose sharply in cows that cycled normally than in cystic, inactive ovary or persistent CL cows. At calving and early postpartum, FFA was higher in inactive ovary and cystic than in normal and persistent CL cows. There was a significant strong positive relationship between IGF-I and BUN, and strong negative relationships between IGF-I and FFA and AST in all groups. There was a positive relationship between serum IGF-I and estradiol in normal cystic and inactive ovary cows. This study found that overconditioned cows during the dry period or at calving, lost more body condition postpartum. These cows also had a deeper and longer period of negative energy balance (NEB), poor liver function and low circulating IGF-I concentrations early postpartum. Such cows were likely to have poor reproductive function as seen in development of cystic ovaries, persistent CL and inactive ovary. Changes in serum IGF-I early postpartum may help predict both nutritional and reproductive status in dairy cattle.
\end{abstract}

KEY WORDS: bovine, IGF-I, ovarian function, postpartum.

J. Vet. Med. Sci. 64(10): 879-885, 2002

It is widely recognized that nutrition affects reproductive function in dairy cows, but the exact mechanisms, that is identification of humoral factors, mediating compounds, metabolic hormones or metabolites by which nutrition causes infertility and affects reproduction function are complex, not well defined, and still need further clarification. Since practical assessment of nutritional intake in normal dairy herds is difficult, assessment of blood metabolites provides a good accurate indirect measure. For energy status, changes in the body condition score, ketone bodies, free fatty acids (FFA) and glucose; for protein, blood urea nitrogen (BUN), albumin and hematocrit, and for liver function, apolipoproteins, lecithin cholesterol acyltransferase (LCAT) and aspartate aminotransferase (AST), have long been used in dairy cattle $[25,33,36,37]$. Recently, insulinlike growth factor-I (IGF-I) has been identified as been greatly affected by nutrition status $[7,9]$. The IGFs have also been shown to greatly influence reproductive function. IGF-I promotes follicle-stimulating hormone (FSH) and luteinizing hormone (LH) -supported steriodogenesis on follicular cells, LH receptor induction, and inhibin synthesis $[1,18]$. In the steroidogenic pathway IGFs have been shown to stimulate the aromatase system [2, 13]. IGF-I also increases the sensitivity of follicular cells to FSH and $\mathrm{LH}$

\footnotetext{
* Correspondence to: Sawamukai, Y., Department of Obstetrics and Gynecology, Graduate School of Veterinary Medicine, Rakuno Gakuen University, 582 Bunkyodai-Midorimachi, Ebetsu, Hokkaido 069-8501, Japan.
}

[30] and is also required for normal corpus luteum (CL) formation and function $[12,21]$. Since all components of the IGF system are found in the hypothalamus and pituitary, IGFs are also thought to be involved in modulating their functions $[15,20]$. Since IGF-I is influenced by nutritional status and has an effect on reproductive function in dairy cows, it could be identified as one of the factors that signal nutritional status in the reproductive axis. Therefore, this study was carried out to investigate the relationship among nutritional status, systemic IGF-I and ovarian function and to see if assessment of IGF-I may be used to predict both nutritional and reproductive status in early postpartum dairy cows.

\section{MATERIALS AND METHODS}

Animals: A total of 27 Holstein-Friesian cows, 10 that cycled normally within 20 days postpartum, 5 diagnosed with follicular cysts, 8 with persistent CL after the first ovulation postpartum and 4 with inactive ovaries, from a herd of 100 cows belonging to the Rakuno Gakuen University farm were used for the study. The animals were aged between 3 and 6 years and calved between December 1999 and October 2000. The cows were kept tied to stalls and exercise was allowed in a large paddock for 3-4 hr after the morning milking. They were fed according to Japanese nutritional standards for dairy cattle [3] to meet their nutritional requirements. Silage, hay and concentrates were fed several 
times a day, and milking was done two times a day. The average milk production for the herd was over $9,000 \mathrm{~kg}$ per 305 day lactation equivalent.

Data acquisition: Beginning from dry off, approximately 60 days prepartum to 60 days postpartum, blood samples were collected in plain tubes and tubes containing heparin. They were collected once per week during the dry period, twice per week 1-2 weeks prepartum, 2-3 times per week postpartum, and more than 3 times per week after diagnosis of cysts and inactive ovary. The samples were collected via tail vein puncture and 2-3 hr or more after feeding. After collection, blood samples for serum were stored at $4^{\circ} \mathrm{C}$ for 20-24 $\mathrm{hr}$ and then centrifuged at $1,700 \times \mathrm{g}$ for $15 \mathrm{~min}$. Serum was decanted and stored at $-30^{\circ} \mathrm{C}$ until concentrations of IGF-I, progesterone and estradiol were determined. Heparinized blood samples were centrifuged at $1,700 \times \mathrm{g}$ for $15 \mathrm{~min}$, and plasma was either stored at $-30^{\circ} \mathrm{C}$ for less than a month or immediately analyzed for FFA, BUN and AST. In addition to IGF-I, FFA, BUN and AST were determined in prepartum samples, and progesterone and estradiol were determined in postpartum samples.

The cows were assigned a BCS (Body condition score, on a scale of $1-5$ with 0.25 increments) by one individual utilizing both visual and tactile techniques as described by Ferguson et al. [16], throughout the study period. Examination of the reproductive tract postpartum was carried out 2-3 times per week by palpation per rectum of the ovaries and uterus. It was done up to 5 times per week after cyst diagnosis. Visual examination of the external genitalia and vaginoscopic examination of the vagina and external cervical orifice was also conducted every 2 weeks. Transrectal ultrasonography with an Echopal II machine (Echopal II EUB405B, Hitachi Medical Corporation, Tokyo, Japan) with a 7.5 MHz real-time linear probe (EUP-033J, Hitachi Medical Corporation, Tokyo, Japan) was performed to confirm palpation per rectum findings, cyst diagnosis and monitor changes 3 times per week. The day of first postpartum ovulation was taken as approximately 3 days before a serum progesterone concentration of $\geq 1.5 \mathrm{ng} / \mathrm{m} l$ was recorded. Follicular cysts were defined as follicular structures $\geq 2.5 \mathrm{~cm}$ in diameter present on one or both ovaries, and by ultrasound had no luteal tissue, with $>1 \mathrm{ng} / \mathrm{m} l$ serum progesterone concentrations in the absence of a CL. Inactive ovary was diagnosed in cows that were not observed in estrus for two months postpartum, had small ovaries, which were either flat and smooth or rounded on rectal palpation, in the absence of a CL. Persistent CL was defined as cows that had a luteal phase (presence of an active CL with progesterone concentration $>1 \mathrm{ng} / \mathrm{ml}$ ) of the estrous cycle $\geq 25$ days, with no uterine infection, service or pregnancy.

Determination of $I G F-I, F F A, B U N$ and AST activity: Serum IGF-I concentrations were determined by radioimmunoassay (RIA) as previously described by Roh et al. [28]. The assay was done after an acid-ethanol extraction of binding proteins [14]. The double antibody RIA used human anti-IGF-I (NHPP, lot \#01), human IGF-I standard (NHPP, lot \#AFP4892898), labeled ${ }^{125}$ IGF-I (Amersham, code
IM172), and goat anti-rabbit gamma globulin (A/rGG, TC1214) as the second antibody. The sensitivity of the RIA was $0.31 \mathrm{ng} / \mathrm{ml}$ and the inter- and intra-assay coefficients of variation $(\mathrm{CV})$ were 10.1 and $8.2 \%$, respectively. Briefly, $50 \mu l$ of serum was added to $2.5 \mathrm{ml}$ of extraction buffer $(12.5 \% 2 \mathrm{~N} \mathrm{HCl}$ and $87.5 \%$ ethanol), mixed and left to stand at room temperature for $30 \mathrm{~min}$. The tubes were then centrifuged at $3,000 \mathrm{rpm}$ for $30 \mathrm{~min}$ at $4^{\circ} \mathrm{C}$, and $500 \mu \mathrm{l}$ of the supernatant was mixed with $200 \mu l$ of neutralization buffer $(0.855 \mathrm{M}$ Tris $\mathrm{Cl})$ to make $\mathrm{pH} 7.2$. One hundred $\mu l$ of this mixture was used in triplicate for the RIA in $10 \times 75 \mathrm{~mm}$ plastic tubes. Twenty-four hours after the addition of human anti-IGF-I, ${ }^{125}$ IGF-I was added and the tubes further incubated for $24 \mathrm{hr}$ at $4{ }^{\circ} \mathrm{C}$. Goat $\mathrm{A} / \mathrm{rGG}$ with $0.4 \%$ normal rabbit serum was added and after $24 \mathrm{hr}$, the tubes were centrifuged at 3,000 rpm for $30 \mathrm{~min}$ at $4{ }^{\circ} \mathrm{C}$. The supernatant was decanted and the radioactivity in the precipitate determined with a gamma counter. Concentrations were determined by means of an inhibition curve generated after dilution of the standard.

FFA, BUN and AST were determined with a biochemical auto-analyzer (TBA-20FR, Toshiba, Tokyo, Japan).

Determination of estradiol and progesterone concentrations: Serum concentrations of estradiol and progesterone were determined by double antibody RIA after extraction with ether as described by Taya et al. [31] and Ribadu et al. [27]. The RIA used antisera to sheep estradiol-17 $\beta$ (GDN 244 ) and progesterone (GDN 337), and ${ }^{125}$ I-labelled estradiol (Amersham, code IM-135) and progesterone (Amersham, code IM-140). For both RIAs donkey anti-sheep gamma globulin was used as second antibody. The sensitivities of the RIAs for estradiol and progesterone were 0.51 $\mathrm{pg} / \mathrm{ml}$ and $0.02 \mathrm{ng} / \mathrm{ml}$, respectively. The intra- and interassay CV were 6.5 and $11.2 \%$ for estradiol and 5.1 and $9.8 \%$ for progesterone.

Statistical analysis: Weekly changes in BCS, hormones and metabolites were compared between groups. Repeated measures analysis of variance with within animal variation as the error term was conducted. Significant differences between two group means were then compared by Student's $t$-test and for more than two means by Dunnett's or Hsu's MCB test. Chi-square analysis was done to check for association between BCS loss and reproductive status early postpartum. To investigate the relationship between IGF-I and FFA, BUN, AST, and estradiol, Pearson product moment and Spearman rank correlation coefficient, if the data were not normally distributed were determined. Differences were considered to be significant at $\mathrm{p}<0.05$ unless stated. Variation in the data was expressed as standard error (SE) of the mean.

\section{RESULTS}

General observations: All 27 cows used in the study calved normally. The mean number of days from parturition to cyst diagnosis was $22.2 \pm 3.0$ (range 16-33) in cows that spontaneously developed cysts. The mean number of days 
from parturition to first ovulation postpartum in the cows that had persistent CL was $23.1 \pm 2.2$ (range 15-33) and $17.5 \pm 0.7$ (range 15-20) in cows that cycled normally within 20 days postpartum.

Changes in BCS in cows of different ovarian status: Changes in BCS during the dry and early postpartum period in the different groups are shown in Fig. 1. BCS was higher during the dry than the postpartum period in all groups of cows. Cows that generally had inactive ovaries early postpartum and those that developed cystic ovaries tended to have higher body condition scores during the dry period and first 4 weeks postpartum than normal cycling cows. All cows in the groups lost body condition from the dry period to early postpartum. As shown in Table 1, between 2 weeks prepartum and 4 weeks postpartum, Inactive ovary cows lost more body condition ( $>0.75$ BCS points) than cows that cycled normally within 20 days postpartum $\left(\chi^{2} \mathrm{p}<0.1\right)$, although there was no significant difference in body condition loss between normal and either cystic or persistent CL cows. There were no significant differences in BCS by 4 weeks postpartum among the groups. Since inactive ovary and cystic cows had higher BCS just before calving, this shows that they lost more condition than normal or persistent CL cows.

\section{Changes in IGF-I in cows of different ovarian status}

General description: As shown in Fig. 2., fluctuations in serum IGF-I were similar in all groups of cows during the dry and early lactation periods. Serum IGF-I concentrations were highest early in the dry period and progressively decreased towards parturition, reaching lowest levels at calving. The IGF-I levels then progressively increased with the increase in the number of days postpartum reaching similar levels by 60 days to those observed during the week before calving but lower than those observed during the rest of the dry period.

Fluctuations in IGF-I during the dry period in cows of different ovarian status early postpartum: Refer to Table 2 and Fig. 2 for a summary. During weeks 6-9 and 3-5 of the dry period serum IGF-I concentrations were lower, in cows that had persistent CLs, than in either cows that cycled normally, inactive or developed cystic ovaries early postpartum. There were no significant differences between normal cows and either inactive ovary, cystic or persistent CL cows. During this time, IGF-I declined more rapidly in inactive ovary cows than in the rest of the groups. During the last two weeks prepartum, IGF-I declined rapidly and there were no significant differences among the groups.

Fluctuations in IGF-I early postpartum in cows of different ovarian status early postpartum: A summary of the fluctuations in serum IGF-I is shown in Table 2 and Fig. 2. In all groups of cows, serum IGF-I concentrations were lowest at parturition and during the first week (days 0-6) after parturition and no significant differences were observed among the groups. In week 2 (days 7-13) postpartum, serum IGFI increased sharply in normal cows and was significantly higher than in inactive ovary, cystic or persistent CL cows. In week 3 (days 14-20) postpartum, serum IGF-I in normal

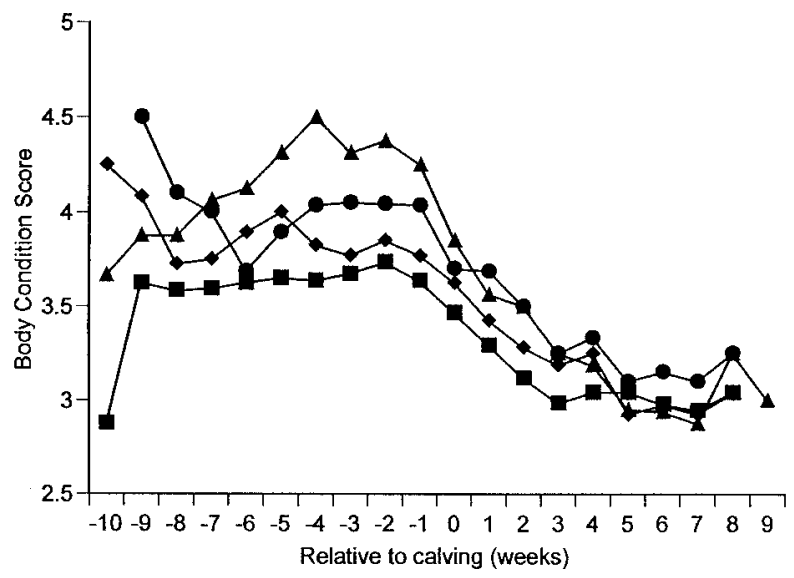

Fig. 1. Mean weekly changes in BCS during the dry and early postpartum periods in cows that cycled normally $(\boldsymbol{\square}, \mathrm{n}=10)$, inactive ovary $(\boldsymbol{\Lambda}, \mathrm{n}=4)$, cystic $(\boldsymbol{O}, \mathrm{n}=5)$ or had persistent $\mathrm{CL}$ $(\diamond, n=8)$ early postpartum. Week 0 : day $0-6$; day 0 is the day of parturition.

Table 1. Chi square analysis of drop in body condition score from 2 weeks prepartum to 4 weeks postpartum compared to cows cycling normally within 20 days postpartum

\begin{tabular}{lccc}
\hline Group & $\begin{array}{c}\mathrm{n}>0.75 \mathrm{BCS} \\
\text { points lost }\end{array}$ & $\mathrm{N}$ & $\mathrm{p}$ \\
\hline Normal & 2 & 10 & \\
Inactive ovary & 3 & 4 & 0.09 \\
Cystic & 3 & 5 & 0.17 \\
Persistent CL & 3 & 8 & 0.38 \\
\hline
\end{tabular}

$\mathrm{n}$ : Number of cows that lost $>0.75$ BCS points.

$\mathrm{N}$ : Total number of cows in group.

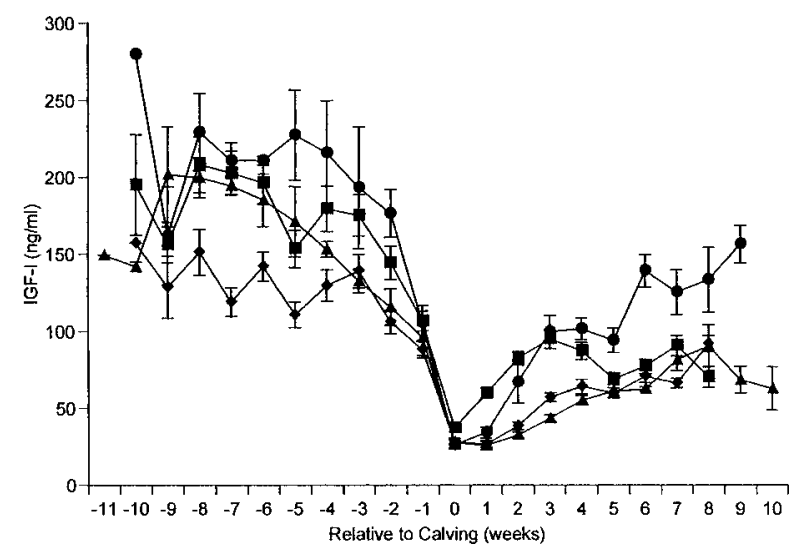

Fig. 2. Mean weekly changes in serum IGF-I during the dry and early postpartum periods in cows that cycled normally $(\boldsymbol{\square}$, $\mathrm{n}=10)$, inactive ovary $(\boldsymbol{\Delta}, \mathrm{n}=4)$, cystic $(\boldsymbol{O}, \mathrm{n}=5)$ or had persistent CL $(\diamond, n=8)$ early postpartum. Week 0 : day $0-6$; day 0 is the day of parturition.

cows increased sharply but continued to increase gradually in inactive ovary and persistent CL cows. During week 3 
Table 2. Changes in serum IGF-I in cows during the dry and early postpartum periods

\begin{tabular}{|c|c|c|c|c|}
\hline \multirow[b]{2}{*}{ Week } & \multicolumn{4}{|c|}{ Group } \\
\hline & $\begin{array}{l}\text { Normal } \\
(\mathrm{n}=10)\end{array}$ & $\begin{array}{l}\text { Anestrous } \\
(\mathrm{n}=4)\end{array}$ & $\begin{array}{l}\text { Cystic } \\
(\mathrm{n}=5)\end{array}$ & $\begin{array}{l}\text { Persistent CL } \\
\quad(\mathrm{n}=8)\end{array}$ \\
\hline-6 to -9 & $199.9 \pm 12.0$ & $198.7 \pm 11.0$ & $204.1 \pm 9.8^{b)}$ & $139.2 \pm 9.7^{\mathrm{a})}$ \\
\hline-3 to -5 & $174.2 \pm 12.0$ & $153.4 \pm 12.0$ & $218.2 \pm 15^{\mathrm{b})}$ & $129.3 \pm 9.1^{\mathrm{a})}$ \\
\hline-1 to -2 & $124.1 \pm 9.0$ & $95.1 \pm 9.6$ & $132.8 \pm 7.6$ & $94.90 \pm 6.7$ \\
\hline 0 & $38.9 \pm 4.0$ & $26.5 \pm 4.4$ & $27.4 \pm 2.1$ & $27.69 \pm 1.6$ \\
\hline 1 & $61.0 \pm 5.4^{b)}$ & $27.8 \pm 4.6^{\mathrm{a})}$ & $34.1 \pm 2.9^{\mathrm{a})}$ & $26.81 \pm 2.4^{\mathrm{a})}$ \\
\hline 2 & $81.3 \pm 6.9^{\mathrm{b})}$ & $33.1 \pm 2.0^{\mathrm{a})}$ & $64.8 \pm 9.4$ & $37.83 \pm 3.9^{\mathrm{a})}$ \\
\hline 3 & $91.5 \pm 8.5$ & $43.5 \pm 2.7^{\mathrm{a})}$ & $97.3 \pm 8.1^{b)}$ & $58.94 \pm 4.7^{\text {a) }}$ \\
\hline 4 & $80.3 \pm 6.3$ & $58.5 \pm 3.3^{\mathrm{a})}$ & $94.2 \pm 6.2^{\mathrm{b})}$ & $67.50 \pm 7.9^{\mathrm{a})}$ \\
\hline 5 to 8 & $79.0 \pm 5.5^{\mathrm{c})}$ & $72.3 \pm 5.3^{\mathrm{c})}$ & $120.8 \pm 6.3^{\mathrm{d})}$ & $70.20 \pm 5.1^{\mathrm{c})}$ \\
\hline
\end{tabular}

Week 0: day $0-6$; day 0 is the day of parturition.

Values are mean $\pm \mathrm{SE}$ in $n \mathrm{~g} / \mathrm{m} l$.

Values in the same row with different superscripts are different. a, b) - $(\mathrm{p}<0.1)$.

$\mathrm{c}, \mathrm{d})-(\mathrm{p}<0.05)$.

postpartum serum IGF-I in normal cows was not significantly different from that in cystic cows but was significantly higher than in inactive ovary and persistent CL cows. A sharp increase in IGF-I was generally observed in normal cows about the time of ovulation. The sharp increase in IGF-I in cystic cows was due to diagnosis of cysts about this time (range 16-33 days). The presence of cysts led to an increase in the production of IGF-I by the ovary and liver. During weeks 4 and 5 serum IGF-I levels in normal cows were not significantly different from those in ovarian dysfunction cows, but during these weeks serum IGF-I in cystic cows was slightly higher than in normal cows and was significantly higher than in both inactive ovary and persistent CL cows. From week 6 until the end of the observation period (approximately 60 days postpartum), serum IGF-I was significantly higher in cystic cows with the persistence of cysts than in normal, inactive ovary or persistent CL cows.

Changes in FFA in cows of different ovarian status: As shown in Fig. 3, in all groups of cows during the dry period until one week prepartum, FFA remained very low fluctuating between 53 and $167 \mu \mathrm{Eq} / l$. In the last week before calving FFA began to increase and reached its highest peak during the first week postpartum and then began to decrease reaching basal levels earlier postpartum in normal and persistent CL cows than in inactive ovary and cystic cows.

During the last two weeks prepartum, although there were

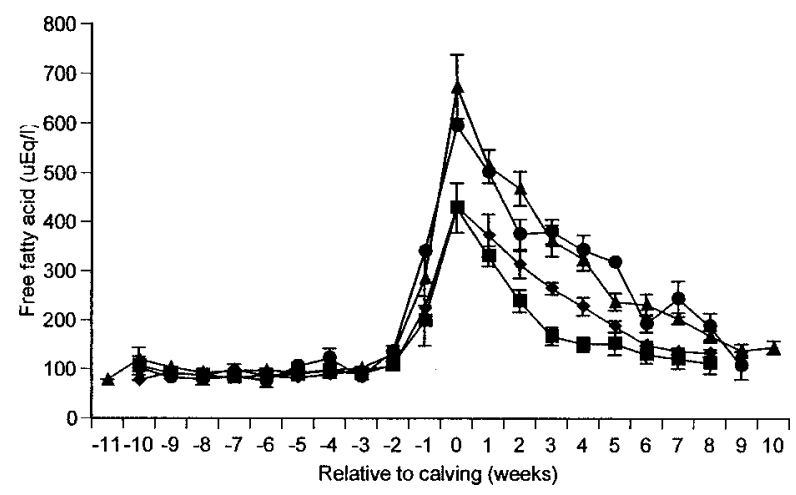

Fig. 3. Mean weekly changes in FFA during the dry and early postpartum periods in cows that cycled normally $(\boldsymbol{\square}, \mathrm{n}=10)$, inactive ovary $(\boldsymbol{\Delta}, \mathrm{n}=4)$, cystic $(\boldsymbol{O}, \mathrm{n}=5)$ or had persistent $\mathrm{CL}$ $(\diamond, \mathrm{n}=8)$ early postpartum. Week 0 : day $0-6$; day 0 is the day of parturition.

no significant differences in FFA among the groups, levels in inactive ovary and cystic cows tended to be higher (Table 3). During weeks 0-3 and 4-7 postpartum, FFA was significantly higher in inactive ovary and cystic than in normal and persistent $\mathrm{CL}$ cows $(\mathrm{p}<0.05)$. FFA was similar in inactive ovary and cystic cows and in normal and persistent CL cows during the same periods.

Changes in BUN in cows of different ovarian status: Fluctuations in BUN levels are summarized in Fig. 4. In all

Table 3. Changes in FFA in cows during the dry and early postpartum periods

\begin{tabular}{lcccc}
\hline \multirow{2}{*}{ Stage } & \multicolumn{4}{c}{ Group } \\
\cline { 2 - 5 } & $\begin{array}{c}\text { Normal } \\
(\mathrm{n}=10)\end{array}$ & $\begin{array}{c}\text { Inactive ovary } \\
(\mathrm{n}=4)\end{array}$ & $\begin{array}{c}\text { Cystic } \\
(\mathrm{n}=5)\end{array}$ & $\begin{array}{c}\text { Persistent CL } \\
(\mathrm{n}=8)\end{array}$ \\
\hline Week 1-2 prepartum & $156.9 \pm 11$ & $236.8 \pm 29$ & $235.2 \pm 26$ & $180.7 \pm 12$ \\
Week 0-3 postpartum & $290.8 \pm 8^{\mathrm{a})}$ & $528.3 \pm 31^{\mathrm{b})}$ & $461.0 \pm 16^{\mathrm{b})}$ & $344.2 \pm 10^{\mathrm{a})}$ \\
Week 4-7 postpartum & $134.9 \pm 6^{\mathrm{a})}$ & $255.8 \pm 15^{\mathrm{b})}$ & $274.0 \pm 11^{\mathrm{b})}$ & $175.0 \pm 6^{\text {a) }}$ \\
\hline
\end{tabular}

a,b) Values in the same row with different superscripts are different $(\mathrm{p}<0.05)$.

Values are the mean $\pm \mathrm{SE}$ in $\mu \mathrm{Eq} / l$.

Week 0 : day $0-6$; day 0 is the day of parturition. 


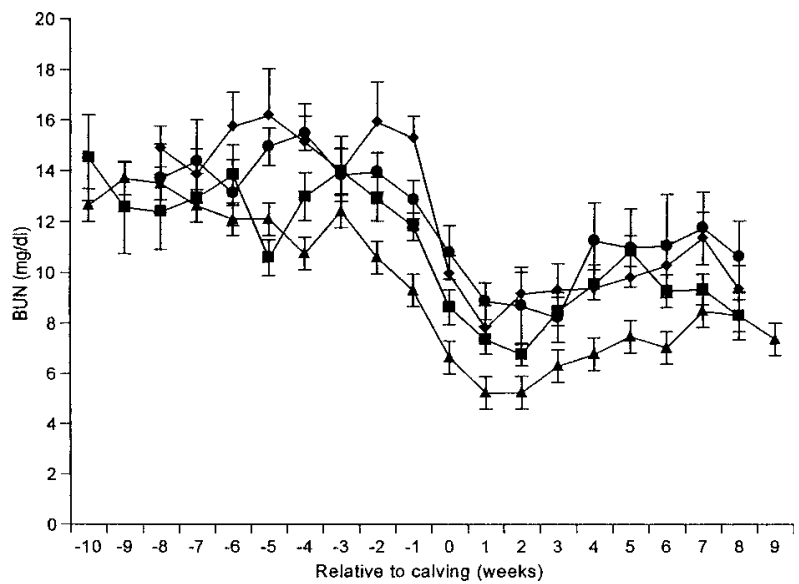

Fig. 4. Mean weekly changes in BUN during the dry and early postpartum periods in cows that cycled normally $(\boldsymbol{\square}, \mathrm{n}=10)$, inactive ovary $(\boldsymbol{\Delta}, \mathrm{n}=4)$, cystic $(\boldsymbol{O}, \mathrm{n}=5)$ or had persistent $\mathrm{CL}$ $(\checkmark, \mathrm{n}=8)$ early postpartum. Week 0 : day $0-6$; day 0 is the day of parturition.

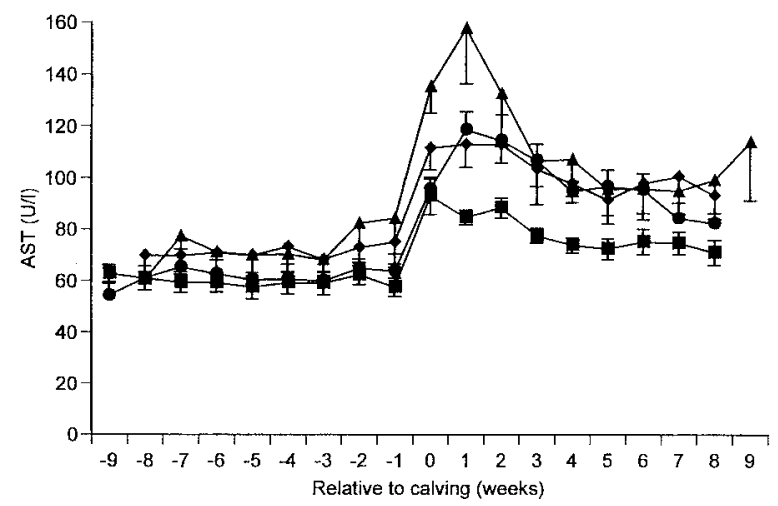

Fig. 5. Mean weekly changes in AST during the dry and early postpartum periods in cows that cycled normally $(\boldsymbol{\square}, \mathrm{n}=10)$, inactive ovary $(\boldsymbol{\Lambda}, \mathrm{n}=4)$, cystic $(\boldsymbol{O}, \mathrm{n}=5)$ or had persistent $\mathrm{CL}$ $(\checkmark, \mathrm{n}=8)$ early postpartum. Week 0 : day $0-6$; day 0 is the day of parturition.

groups of cows BUN levels were within the normal range $(10-16 \mathrm{mg} / \mathrm{d} l)$, and higher during the dry period than postpartum. BUN levels were similar among the groups fluctuating between 10.6 and $15.9 \mathrm{mg} / \mathrm{d} l$, beginning from dry off to 3 weeks prepartum but tended to be higher in cystic and persistent CL cows and lower in inactive ovary cows. During the last two weeks prepartum BUN levels were declining sharply, and were lower than $10.2 \mathrm{mg} / \mathrm{d} l$ in inactive ovary cows. BUN levels continued to decline through the first week postpartum and reached their nadir at 2-3 weeks postpartum in all groups of cows. BUN levels then rose sharply in cystic, persistent CL and normal cows and gradually in inactive ovary cows. During the postpartum period weekly BUN levels were similar fluctuating between 6.8 and $9.5 \mathrm{mg} / \mathrm{d} l$ in normal cows, 8.2 and $11.75 \mathrm{mg} / \mathrm{d} l$ in cystic cows, 7.8 and $11.4 \mathrm{mg} / \mathrm{d} l$ in persistent CL cows and lower fluctuating between 5.2 and $8.5 \mathrm{mg} / \mathrm{d} l$ in inactive ovary
Table 4. Coefficients of correlation between weekly changes in serum IGF-I and FFA, BUN, AST and estradiol in cows of different reproductive status

\begin{tabular}{lcccc}
\hline Group & FFA & BUN & AST & Estradiol \\
\hline Normal $(\mathrm{n}=10)$ & -0.74 & 0.86 & -0.74 & 0.65 \\
Cystic $(\mathrm{n}=5)$ & -0.97 & 0.84 & -0.82 & 0.70 \\
Inactive ovary $(\mathrm{n}=4)$ & -0.86 & 0.96 & -0.87 & 0.70 \\
Persistent CL $(\mathrm{n}=8)$ & -0.87 & 0.76 & -0.90 & $0.21^{\text {a) }}$ \\
\hline
\end{tabular}

a) $\mathrm{p}=0.31$.

cows.

Changes in AST in cows of different ovarian status: Fluctuations in AST levels are summarized in Fig 5. In all groups of cows mean weekly serum AST levels tended to be higher in the postpartum period than in the dry period. AST levels were similar among the groups, fluctuating between 54 and $85 \mathrm{U} / l$ during the dry period, but tended to be higher in persistent CL and inactive ovary cows, and lower in cystic and normal cows. With parturition, AST levels then rose sharply during the first week postpartum reaching peak concentrations at one and two weeks postpartum in normal and the rest of the groups, respectively. AST levels then declined gradually in normal, cystic and persistent CL cows and sharply in inactive ovary cows until week 5 , and then remained fairly constant until 9 weeks postpartum. During weeks 1-2 postpartum AST levels were higher than the normal recommended for cows $(45-110 \mathrm{U} / l)$ in cystic, persistent CL and inactive ovary cows. During the postpartum period weekly AST levels were highest in inactive ovary cows fluctuating between 95 and $157 \mathrm{U} / l$. AST levels were similar in persistent CL and cystic cows fluctuating between 91 and 113 and 82 and $114 \mathrm{U} / l$, respectively. AST was lowest in normal cows fluctuating between 71 and $93 \mathrm{U} / l$.

Relationship of IGF-I to FFA, BUN and AST: Coefficients of correlation between IGF-I and FFA, BUN, AST and estradiol in cows of different reproductive status postpartum are summarized in Table 4. During the dry and postpartum period, a significant positive relationship was observed between IGF-I and BUN, and significant negative relationships between IGF-I and FFA and AST. During the postpartum period, significant positive relationships were observed between IGF-I and estradiol in normal, cystic and inactive ovary cows. The relationship between IGF-I and estradiol in persistent CL cows was not significant.

\section{DISCUSSION}

It was found in this study that the serum IGF-I concentration was lowest at parturition and during the first week postpartum in all groups of cows and was not significantly different among the groups. This result is similar to that observed in other studies [22, 32]. Lucy [22] reported that the low serum IGF-I about the time of parturition, was associated with a decrease in IGF-I mRNA and a decrease in total liver ST (somatropin) receptor mRNA. A rapid decline in ST receptor 1A mRNA that controls the binding of 
growth hormone to the liver and production of IGF-I by the liver is especially important. The current study also found that serum IGF-I concentrations were higher and rose more sharply in cows which cycled normally within 20 days postpartum than in cows which developed cystic ovaries, inactive ovary or persistent CLs. A positive and significant relationship between estradiol and IGF-I was also observed in cows that cycled normally, suggesting that IGF-I is important for follicular development. Other studies have associated IGF-I concentrations with follicular development $[4,5,12,17,23,32]$. Beam and Butler [4, 5], also found that plasma IGF-I levels were $40-50 \%$ higher during the first 2 weeks postpartum in dairy cows in which the first dominant follicle (DF) ovulated compared to those with non-ovulatory follicles and, Lucy et al. [23] reported a positive correlation between the estrogen : progesterone ratio in follicular fluid and plasma IGF-I. Our study also observed a sharp increase in IGF-I about the time of ovulation in cows that cycled normally. This is similar to the high IGF-I at estrus in goats reported by Hashizume et al. [19]. These findings suggest that normal follicular development may be associated with an early rise in IGF-I postpartum.

The positive and negative relationship between IGF-I and BUN and IGF-I and FFA, respectively, in all groups of cows show that IGF-I is affected by both protein and energy intake in cows. Other studies have also reported that serum IGF-I concentrations are influenced by energy status $[4,5$, $10,24]$, and are negatively correlated with FFA [26, 29]. This was clearly demonstrated in this study about the peripartum negative energy balance (NEB) period, when FFA was highest and IGF-I lowest.

The liver is the main organ for production of IGF-I. A negative relationship between AST and IGF-I was observed in this study. This shows that poor liver function leads to a decrease in production of IGF-I and serum concentrations. Coinciding with lower IGF-I concentrations during the first two weeks postpartum in inactive ovary, cystic and persistent CL cows, AST levels were higher than in normal cows, in each case. This study also found that inactive ovary and cystic cows had higher BCS and lost more body condition than normal cows from the dry to the postpartum period. Similarly, FFA was also higher the first 8 weeks postpartum in inactive ovary and cystic cows than in normal cows. As mentioned above, inactive ovary, cystic and persistent CL cows also had lower IGF-I concentrations at calving. The results of this study showed that cows that were overconditioned during the dry period or at calving lost more body condition postpartum. These cows also had a deeper and longer period of negative energy balance (NEB), poor liver function and low circulating IGF-I concentrations early postpartum. Such cows are likely to have poor reproductive function as seen in the development of cystic ovaries, persistent CLs and inactive ovary. Many studies have shown that overconditioned cows at calving are likely to have poor reproductive function (retained fetal membranes, inactive ovary, cystic ovaries or endometritis) and suffer metabolic diseases (hepatic lipidosis, ketosis or left displacement of

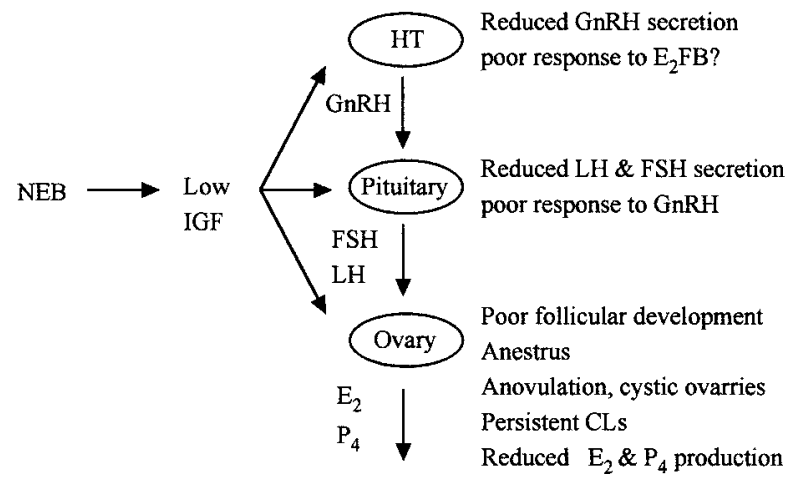

Fig. 6. Proposed effect of low serum IGF-I on the reproductive axis early postpartum in dairy cows. HT: Hypothalamus. $\mathrm{E}_{2}$ : Estradiol. $\mathrm{P}_{4}$ : Progesterone. FB: Feedback.

the abomasum) $[8,34,35]$, leading to infertility.

NEB influences LH pulsatility that seems crucial for the onset and timing of postpartum ovarian function $[6,11]$. As mentioned above and shown in Fig. 6, NEB leads to low serum IGF-I levels, and since IGF-I reception and production have been demonstrated on the reproductive axis (hypothalamus, pituitary and ovary), it may be that together they affect gonadotropin releasing hormone, FSH and LH secretion and follicular development early postpartum. Therefore low serum IGF-I through NEB early postpartum may lead to poor reproductive function.

In conclusion, the findings of this study suggest that changes in serum IGF-I early postpartum may help predict both nutritional and reproductive status in dairy cattle. IGFI may therefore be identified as one of the long sought factors that signal nutritional status to the reproductive axis.

ACKNOWLEDGEMENTS. The authors are very grateful to Dr. A. F. Parlow, NHPP for kindly providing of anti hIGF-I and hIGF-I, and to Dr. G. D. Niswender (Animal Reproduction and Biotechnology Laboratory, Colorado State University, U.S.A.) for antisera to both estradiol-17 $\beta$ and progesterone. The authors are indebted to Prof. Dr. H. Hidari, Dr. H. G. Lee, Mr. Nou Vonika and others at the Laboratory of Animal production, Department of Animal Science, Obihiro Agriculture University, Japan for their invaluable help with the IGF-I assay and to Hokkaido NOSAI for kindly providing of facilities for the determination of blood metabolites. This work was partially supported by a grant-in-aid for cooperative research from Rakuno Gakuen University 2001-6.

\section{REFERENCES}

1. Adashi, E. Y. 1992. Intraovarian regulation: the IGF-I example. Reprod. Fertil. Dev. 4: 497-504.

2. Adashi, E. Y., Resnick, C. E., D’Ercole, J., Svoboda, M. E. and Van Wyk, J. J. 1985. Insulin-like growth factors as intraovarian regulators of granulosa cell growth and function. Endocr. Rev. 6: $400-420$.

3. Agriculture Forestry and Fisheries Research Council Secretar- 
iat, MAFF. 1994. Japanese Feeding Standard for Dairy Cattle. Central Association of Livestock Industry, Tokyo (in Japanese).

4. Beam, S. W. and Butler, W. R. 1997. Energy balance and ovarian follicle development prior to the first ovulation postpartum in dairy cows receiving three levels of dietary fat. Biol. Reprod. 56: $133-142$.

5. Beam, S. W. and Butler, W. R. 1998. Energy balance, metabolic hormones, and early postpartum follicular development in dairy cows fed prilled lipid. J. Dairy Sci. 81: 121-131.

6. Beam, S. W. and Butler, W. R. 1999. Effects of energy balance on follicular development and first ovulation in postpartum dairy cows. J. Reprod. Fertil. (Suppl.) 54: 411-424.

7. Breier, B. H., Bass, J. J., Butler, J.H. and Gluckman, P. D. 1986. The somatotrophic axis in young steers: influence of nutritional status on pulsatile release of growth hormone and circulating concentrations of insulin-like growth factor I. $J$. Endocrinol. 111: 209-215.

8. Breukink, H. J. and Wensing, T. H. 1998. Pathophysiology of the liver in high yielding dairy cows and its consequences for health and production. The Bovine Practitioner 32: 74-78.

9. Buonomo, F. C., Grohs, D. L., Baile, C. A. and Campion, D. R. 1988. Determination of circulating levels of insulin-like growth factor II (IGF-II) in swine. Domest. Anim. Endocrinol. 5: 233-329.

10. Butler, W. R. 2000. Nutritional interactions with reproductive performance in dairy cattle. Anim. Reprod. Sci. 60-61: 449-457.

11. Butler, W. R. and Smith, R. D. 1989. Interrelationships between energy balance and postpartum reproductive function in dairy cattle. J. Dairy Sci. 72: 767-783.

12. Chase, C. C., Kirby, C. J., Hammond, A. C., Olson, T. A. and Lucy, M. C. 1998. Patterns of ovarian growth and development in cattle with a growth hormone receptor deficiency. J. Anim. Sci. 76: 212-219.

13. Davoren, J. B., Kasson, B. G., Hsueh, A. J. W. and Li, C. H. 1986. Specific Insulin-like growth factor I-and II- binding sites on rat granulosa cells: relation to IGF action. Endocrinology 119: $2155-2162$.

14. Daughaday, W. H., Mariz, I. K. and Blethen, S. L. 1980. Inhibition of access of bound somatomedin to membrane receptor and immunobinding sites: a comparison of radioreceptor and radioimmunoassay of somatomedin in native and acid-ethanolextracted serum. J. Clin. Endocrinol. Metab. 51: 781-788.

15. D'Ercole, A. J., Ye, P., Calikoglu, A. S. and Gutierrez-Ospina, G. 1996. The role of the insulin-like growth factors in the central nervous system. Mol. Neurobiol. 13: 227-255.

16. Ferguson, J. D., Galligan, D. T. and Thomsen, N. 1994. Principal descriptions of body condition scores in Holstein cows. $J$. Dairy Sci. 77: 2695-2703.

17. Ginger, R., Faisser, D., Busato, A., Blum, J. and Kupfer, U. 1997. Blood parameters during early lactation and their relationship to ovarian function in dairy cows. Reprod. Domest. Anim. 32: 313-319.

18. Guidice, L. C. 1992. Insulin-like growth factors and ovarian follicular development. Endocr. Rev. 13: 641-669.

19. Hashizume, T., Ohtsuki, K. and Matsumoto, N. 2000. Plasma insulin-like growth factor-I concentrations increase during the estrous phase in goats. Domest. Anim. Endocrinol. 18: 253-263.

20. Hiney, J. K., Ojeda, S. R. and Dees, W. L. 1991. Insulin-like growth factor 1: a possible metabolic signal involved in the regulation of female puberty. Neuroendocrinology 54: 420-423.

21. Leeuwenberg, B. R., Hudson, N. L., Moore, L. G., Hurst, P. R. and McNatty, K. P. 1996. Peripheral and ovarian IGF-I con- centrations during the ovine oestrous cycle. J. Endocrinol. 148: 281-289.

22. Lucy, M. C. 2000. Regulation of ovarian follicular growth by somatotropin and insulin-like growth factors in cattle. J. Dairy Sci. 83: 1635-1647.

23. Lucy, M. C., Berk, J., Staples, C. R., Head, H. H., Sota, R. L. D. and Thatcher, W. W. 1992. Follicular dynamics, plasma metabolites, hormones and insulin-like growth factor I (IGF-1) in lactating cows with positive or negative energy balance during the preovulatory period. Reprod. Nutr. Dev. 32: 331-341.

24. McGuire, M. A., Bauman, D. E., Cohick, W. S. and Dwyer, D. A. 1995. Nutritional modulation of the somatotropin/ insulinlike growth factor system: response to feed deprivation in lactating cows. J. Nutr. 125: 493-502.

25. Nakagawa, H., Oikawa, S., Oohashi, T. and Katoh, N. 1997. Decreased serum lecithin cholesterol acyltransferase activity in spontaneous cases of fatty liver in cows. Vet. Res. Commun. 21: $1-8$.

26. Nishimura, K., Shimizu, S., Urata, H., Aoyama, Y., Kojima, T., Matta, M., Kawabata, Y., Uchiyama, M., Sakuragi, K. and Ohnishi, Y. 2000. The relationship between serum Insulin-like Growth Factor-I and changes in body weight in early-lactating cows. J. Vet. Epidemiol. (Jpn.) 2: 89-96.

27. Ribadu, A. Y., Nakada, K., Moriyoshi, M., Zhang, W. C., Tanaka Y. and Nakao, T. 2000. The role of LH pulse frequency in ACTH-induced ovarian follicular cysts in heifers. Anim. Reprod. Sci. 64: 21-31.

28. Roh, S. G., Matsunaga, N., Hidaka, S. and Hidari, H. 1996. Characteristics of growth hormone secretion responsiveness to growth hormone-releasing peptide-2 (GHRP-2 or KP102) in calves. Endocr. J. 43: 291-298.

29. Rutter, L. M., Snopek, R. and Manns, J. G. 1989. Serum concentrations of IGF-1 in postpartum beef cows. J. Anim. Sci. 67: 2060-2066.

30. Spicer, L. J. and Echternkamp, S. E. 1995. The ovarian insulin and insulin like growth factor system with an emphasis on domestic animals. Domest. Anim. Endocrinol. 12: 223-245.

31. Taya, K., Watanabe, G. and Sasamoto, S. 1985. Radioimmunoassay for progesterone, testosterone and estradiol- $17 \beta$ using ${ }^{125}$ I-iodohistamine radioligands. Jpn. J. Anim. Reprod. 31: 186-197.

32. Thatcher, W. W., de la Sota, R. L., Schmitt, E. J., Diaz, T. C, Badinga, L., Simmen, F. A., Staples, C. R. and Drost, M. 1996. Control and management of ovarian follicles in cattle to optimize fertility. Reprod. Fertil. Dev. 8: 203-217.

33. Uchida, E., Katoh, N. and Takahashi, K. 1992. Induction of fatty liver in cows by ethionine administration and concomitant decreases of serum apolipoproteins B-100 and A-I concentrations. Am. J. Vet. Res. 53: 2035-2042.

34. Wallace, R. L. 1996. Body condition scoring and reproduction in dairy cattle. pp. 93-99. In: Society for Theriogenology Proceedings for Annual Meeting, Kansas City, Missouri.

35. Weaver, L. D. 1987. Effects of nutrition on reproduction in dairy cows. Vet. Clinics North Am., Food Anim. Pract. 3: 513532.

36. Whitaker, D. A. 2000. Use and interpretation of metabolic profiles. pp. 89-107. In: The Health of Dairy Cattle (Andrews, A. H. ed.), Blackwell Science Ltd., London.

37. Yamamoto, M., Nakagawa-Ueta, H., Katoh, N. and Oikawa, S. 2001. Decreased concentration of serum apolipoprotein C-III in cows with fatty liver, ketosis, left displacement of the abomasum, milk fever and retained placenta. J. Vet. Med. Sci. 63: 227-231. 